This item was submitted to Loughborough's Research Repository by the author.

Items in Figshare are protected by copyright, with all rights reserved, unless otherwise indicated.

\title{
Consumers' perceived functions of and attitude toward corporate sponsors of small-scale amateur sporting event
}

PLEASE CITE THE PUBLISHED VERSION

http://dx.doi.org/10.3727/152599516X14643674421771

\section{PUBLISHER}

(c) Cognizant, LLC.

\section{VERSION}

AM (Accepted Manuscript)

\section{PUBLISHER STATEMENT}

This work is made available according to the conditions of the Creative Commons Attribution-NonCommercialNoDerivatives 4.0 International (CC BY-NC-ND 4.0) licence. Full details of this licence are available at: https://creativecommons.org/licenses/by-nc-nd/4.0/

\section{LICENCE}

CC BY-NC-ND 4.0

\section{REPOSITORY RECORD}

Low, Bernice Xiao Ting, and Do Young Pyun. 2019. "Consumers' Perceived Functions of and Attitude Toward Corporate Sponsors of Small-scale Amateur Sporting Event”. figshare. https://hdl.handle.net/2134/20864. 
Running Head: Perceived Functions and Attitude in Small-Scale Sport Events

Consumers' Perceived Functions of and Attitude toward Corporate Sponsors of Small-Scale Amateur Sporting Events 


\begin{abstract}
Aspiring to become a sporting nation, one recommendation from Singapore's Vision 2030 is to develop a sustainable resourcing model, by encouraging more corporate companies to sponsor sporting events. This research aimed to identify the perceived functions of corporate sponsors, which influenced consumers to develop positive attitudes toward these sponsors. 210 undergraduate students participated in this study. The five perceived functions of corporate sponsors were ubiquity, sincerity, credibility, sponsor-event fit, and profit-orientation. It was hypothesised that perceived ubiquity and profit-orientation negatively influenced consumers' attitude while perceived sincerity, credibility, and sponsor-event fit were positive influences. A multiple regression test showed perceived ubiquity and sponsor-event fit as significant functions which positively influenced consumers' attitude toward corporate sponsors of small-scale sporting events.
\end{abstract}

Keywords: corporate sponsorship, small-scale events, perceived functions, attitude 


\section{Introduction}

Aspiring to become a sporting nation, Singapore has hosted various large-scale sporting events in recent years, such as the first night race in the Formula One series in 2008, the first Asian Youth Games in 2009, and the inaugural Youth Olympic Games in 2010. The Youth Olympic Games, which was termed by the Prime Minister of Singapore, Lee Hsien Loong, as the "new era for sports in Southeast Asia" (Chan, n.d, p. 3), attracted a total of 7,588 athletes and officials and the involvement of 50,688 volunteers, working staff and contractors (Ministry of Culture, Community and Youth, 2010). Roche (2000) defined a large-scale event as "large-scale cultural (including commercial and sporting) events, which have a dramatic character, mass popular appeal and international significance" (p. 1). The opportunity to host such large-scale sporting events is often sought after by many countries as it not only promotes urban development, but also creates employment opportunities and economic growth (Baum \& Lockstone, 2007).

However, more than just hosting large-scale sporting events, people of all ages have to be actively involved in sporting events, directly or indirectly, in order for Singapore to be considered a true sporting nation. One way to encourage greater participation and healthy lifestyle among the grassroots level is to organise more small-scale amateur sporting events (Department for Culture, Media and Sport, 2012). Higham (1999) defined small-scale sporting events as "regular season sporting competitions, international sporting fixtures, domestic competitions, Masters or disabled sports, and the like" (p. 87). They may include school-based sporting events (e.g., the annual Singapore University Games), and community-based sporting events (e.g., Pioneer Road Run) with a small group of participants (Dixon, Henry, \& Martinez, 2013; Yusof, Omar-Fauzee, Shah, \& Geok, 2009). 
Contrary to popular beliefs, small-scale amateur sporting events can improve the quality of life as they have more long-term social, health and psychological benefits, as compared to large-scale sporting events (Jordan, 2012; Tzetzis, Alexandris, \& Kapsampeli, 2014). Smallscale sporting events are usually more manageable and require less monetary support since they tap on existing resources and infrastructure (Tzetzis et al., 2014; Walo, Bull, \& Breen, 1996). For this reason, small-scale sporting events can be organised on a more frequent basis, for greater community involvement and participation (Tzetzis et al., 2014). Consequently, the contributions and involvement of the community would foster a sense of pride and belonging among them (Tzetzis et al., 2014). Such small-scale events can also increase the number of platforms for amateur athletes to gain exposure and experience (Kng, 2013).

To support more sporting events, Singapore's Vision 2030 has recommended the development of a sustainable resourcing model, by having alternate sources of funding in a bid to reduce the dependence on the government for sport development (Vision 2030, n.d.). One major source of funding is corporate sport sponsorship, which is defined as "the provision of assistance either financial or in-kind, to a sport activity, event, team or facility by a commercial organisation for the purpose of achieving commercial objectives" (Meenaghan, 1983, p. 9). The Singapore government aims to "encourage Corporate Singapore to come forward and build longterm relationships with the sports fraternity" (Lim, 2012, para. 6). As such, research on garnering more corporate sponsorship for the sporting industry is necessitated.

While it is of no surprise that corporate sponsors are eager to be part of large-scale sport events given the benefits as mentioned earlier, this might not hold true for small-scale sporting events. One perennial issue faced by small-scale sporting events is the difficulty in garnering funds to manage the event. Consequently, event organisers often look to fund-raising activities to 
finance the events (Zinger \& O’Reilly, 2010). Unlike small-scale sporting events, large-scale sporting events often gain huge publicity globally through the media (Hlabane, n.d.). For instance, 2012 London Olympic Games had more than 219 million viewers, making it the most watched television event in the American history (International Olympic Committee, 2013). Since media exposure makes sponsorship more cost-effective than purchasing television commercials, and it is also one of the criteria in determining the success of a sponsorship, the higher media exposure makes large-scale sporting events more appealing in attracting corporate sponsors (Copeland \& Frisby, 1996).

Thus, before participating more actively in local small-scale amateur sporting events, there is a need for potential corporate sponsors to understand how to best position themselves to reach out to their target market, increase their sponsorship effectiveness, and also, appreciate the benefits accrued from their sponsorships. Moreover, event organisers should develop more effective sponsorship proposals for small-scale sporting events to attract corporate sponsors. Past literature identified possible ways to enhance consumers' positive attitude toward the corporate sponsors of large-scale sporting events (Eagleman \& Krohn, 2012). However, little research has focused on sponsorship in small-scale amateur sporting events. Lack of such research makes it more difficult for small-scale sporting event organisers to plan and develop effective sponsorship proposals and for potential sponsors to be convinced about the benefits associated with their involvement. Therefore, this research was designed to fill the gap in existing sport sponsorship literature, which focused mainly on corporate sports sponsorship in large-scale professional sporting events such as the Olympic Games, rather than small-scale sporting events. This research aimed to enhance the effectiveness of corporate sport sponsorship for small-scale amateur sporting events, for both event organisers and potential corporate sponsors, by 
identifying which perceived functions of corporate sponsors would influence consumers to develop a positive attitude toward these sponsors.

\section{Conceptual Background}

Since her independence, Singapore has been actively developing her sporting scene through small-scale community sporting events such as big walks and sports tournaments (Hoi, 1999). These events encouraged citizens to lead a healthy lifestyle and foster unity among the different races and backgrounds. Further, these small-scale amateur sporting events also saw the involvement of youths in the sporting scene, which helped to "mould youths into basic good citizens and mitigate the extremes of delinquency and crime" (Hoi, 1999, p. 6).

The proliferation of small-scale amateur sporting events not only benefits the local population, but also aid small corporate companies who may be interested in sponsoring sporting events, but struggle to sponsor large-scale sporting events which often involve huge sum of money (Mack, 1999).

\section{Attitude toward Corporate Sport Sponsors}

Attitude has been defined as "a learned predisposition to respond in a consistently favourable manner with respect to a given object" (Fishbein \& Ajzen, 1975, p. 6). The affective components of attitude focused in this research, were "positive and/or negative emotions associated with the attitude object, such as excitement or sadness" (See, Petty, \& Fabrigar, 2008, p. 939). Consumers can develop their attitude toward corporate sponsors through their personal experiences or information gathered from their environment (Asiegbu, Powei, \& Iruka, 2012). The attitude toward sport sponsors is defined by Keller (2003) as "consumer's overall evaluations to any brand-related information" (p. 596).

When consumers appreciate sponsorship efforts, it often translates to positive attitude 
toward the sponsors (Madrigal, 2001). Based on past literature, a consumer's attitude toward corporate sponsors is regarded as one of the indicators of the effectiveness of sponsorship (Alexandris, Tsaousi, \& James, 2007; Stipp \& Schiavone, 1996). Consumers' attitude, which is influenced by their perceptions of the different functions of sponsorship, is important in predicting their behavioural response such as purchase intentions (Ajzen, 2001; Asiegbu et al., 2012). Such purchase intentions are critical in gauging sponsors' abilities to achieve their sponsorship objectives (Koo, Quarterman, \& Flynn, 2006; Speed \& Thompson, 2000). For this reason, this study aimed to focus on identifying ways that encouraged consumers to develop a positive attitude toward corporate sponsors.

\section{Perceived Functions of Corporate Sponsors}

Over the years, corporate sport sponsorship has become a popular marketing platform for corporate companies due to the more cost-effective method in reaching their target markets as compared to advertising (Abratt \& Grobler, 1989). Through corporate sponsorships, companies may also get to enjoy potential tax rebates, display their involvement with the community, and more importantly, increase sales, enhance their corporate image and raise brand awareness (Gwinner, 1997; Weight, Taylor, \& Cuneen, 2010). Undeniably, corporate sport sponsorship is essential to stimulate the growth of the sporting scene, and the lack of corporate sponsorship may hinder the development of sporting scene (Assimakopoulos, 1993).

Five perceived functions of corporate sponsors were identified and conceptualised. These functions were used to understand how consumers' perceptions would affect consumers' attitude toward corporate sponsors of small-scale amateur sporting events in Singapore.

Perceived ubiquity of the sponsor. Alay (2008) stated that the ubiquity of a sponsor is the "frequency and the selectivity of a corporation for sponsorship" (p. 17). Previous sponsorship 
research had suggested that corporate sponsors, who were involved in many sponsorship activities concurrently, received less recall and reaction from the consumers (Speed \& Thompson, 2000). This negative association was more evident in the aspect of consumers' interest and use of the sponsoring company's brand or services (Speed \& Thompson, 2000). Essentially, consumers would perceive sponsors who had a high level of ubiquity and were unselective in their sponsorship, as less dedicated and less credible because of the divided attention and efforts given to each event that they sponsored (Alay, 2008; Speed \& Thompson, 2000).

Hypothesis 1: Perceived ubiquity of the sponsor negatively influences consumers' attitude toward corporate sponsors of small-scale amateur sporting events in Singapore. Perceived sincerity of the sponsor. Past sponsorship literature had identified a positive relationship between consumers' perception of the corporate sponsor's sincerity and their attitude toward the sponsor (Kim, Ko, \& James, 2011; Speed \& Thompson, 2000). This positive correlation implied that the motivations of the corporate sponsors did influence consumers' reactions toward the sponsorship activity (Speed \& Thompson, 2000). Past research also revealed that sponsors were able to reinforce and enhance their image when their sponsorships were perceived to be motivated by altruism, on the basis of attribution theory (Rifon, Choi, Trimble, \& Li, 2004). Consumers would tend to perceive sponsors of sporting events as doing goodwill, rather than for commercial purposes, when they were seen as playing important roles such as making the event possible, benefitting the community or a sporting team (Alexandris et al., 2007; Gwinner, 1997), and more so when consumers enjoyed and appreciated those sponsored events (Shahrokh, Khazaee, \& Hashemi, 2013). As defined by Shahrokh et al. (2013), goodwill is the "positive attitude of the consumers toward a sponsor company supporting their 
favourite event or team and makes them support their favourite event or team enthusiastically" (p. 93). Evidently, positive attitude toward the sponsor would be developed when consumers recognise the perceived sincerity of the corporate sponsor (Alexandris et al., 2007; Shahrokh et al., 2013).

Hypothesis 2: Perceived sincerity of the sponsor positively influences consumers' attitude toward corporate sponsors of small-scale amateur sporting events in Singapore.

Perceived credibility of the sponsor. As defined by Erdem and Swait (2004), brand credibility is the "believability of the product information contained in a brand, which requires that consumers perceive that the brand have the ability (i.e., expertise) and willingness (i.e., trustworthiness) to continuously deliver what has been promised" (p. 192). When corporate companies are affiliated with sporting events through corporate sports sponsorship, their marketing efforts can then be more justified and supported, which makes them more credible and plausible (McDonald, 1991). The credibility of a company is important as it allows consumers to be more receptive toward the company, and information from the company can be passed on to consumers more effectively (Baek, Kim, \& Yu, 2010; Hanzaee \& Taghipourian, 2012). Since credibility of the sponsoring company has been found to influence consumers' attitude toward the sponsor, more companies are beginning to place emphasis on building an image that depicts them as trustworthy and having the expertise (Hanzaee \& Taghipourian, 2012; Rifon et al., 2004).

Hypothesis 3: Perceived credibility of the sponsor positively influences consumers' attitude toward corporate sponsors of small-scale amateur sporting events.

Perceived sponsor-event fit. According to Simmons and Becker-Olsen (2006), a sponsor-event fit "embodies the idea of transferability of expertise or synergies in activities, such 
as when there is similarity in products, technologies, or markets or complementarity of skills and activities" (p. 155). A fit between the sponsoring company and the sponsored event is perceived when there is relevance, relatedness and compatibility (Pham \& Johar, 2001; Rifon et al., 2004; Ruth \& Simonin, 2003). Previous studies on sponsorship found that such fit was significant in affecting consumers' attitude toward the sponsor, and consumers who perceived the sponsor and event as fit were more inclined to develop a positive attitude toward the corporate sponsor, than those who perceived the fit as incongruent (Koo et al., 2006; Stipp \& Schiavone 1996; Walker, Hall, Todd, \& Kent, 2011).

Gwinner (1997) proposed two types of fit between an event and the sponsor, namely functional and image-based. Functional fit occurs when the product or service sponsored is being utilised during the event itself (e.g., Adidas sponsors the match balls for a soccer tournament) (Gwinner, 1997). An image-based fit occurs when the image of the event is associated with the image of the corporate sponsor (e.g., Red Bull sponsors extreme sports; Gwinner, 1997). This is because Red Bull and extreme sports both portray similar images of being adventurous and energetic. These functional and image-based similarities are essential to establish a stronger fit between the event and sponsor, resulting in an increase in the possibility of an image transfer within consumers' minds (Gwinner, 1997; Howard \& Crompton, 2004). This concept of image transfer from the sponsored event to the sponsoring company mirrors the meaning transfer from the celebrity endorser to the brand (Gwinner, 1997; McDaniel, 1999). Further, sponsorship literature had suggested that a good image fit between the celebrity endorser and the brand led to a more positive attitude and brand recall from the consumer (Misra \& Beatty, 1990). Similarly, when consumers perceived a good fit between the sponsored event and the sponsoring company, their positive attitude toward the event were more likely passed on to the sponsoring company 
(Gwinner, 1997; Keller, 1993).

Hypothesis 4: The level of perceived fit between the sponsoring company and the sponsored event positively influences consumers' attitude toward corporate sponsors of small-scale amateur sporting events.

Perceived profit-orientation of the sponsor. Unlike advertising which "creates the message using a mixture of visuals, vocals and context", sponsorship is deemed as a "mute, nonverbal medium” (Meenaghan, 1991, p. 8). Prior sponsorship literature found that corporate sponsors who portrayed themselves as being obtrusive and overly prominent in their marketing attempts were deemed as sponsors who were motivated by profits, commercial purposes and not altruism (Carrillat \& D’Astous, 2013; Meenaghan, 2001). For instance, when sponsors' promotional messages incorporated brand-level information such as their tag lines or logos, consumers would tend to perceive the corporate sponsorship activity as more profit and commercially-driven (Rifon et al., 2004). It had been proven that consumers favoured corporate sponsors who demonstrated altruism through their sponsorship activities, rather than those who sought profits. Consequently, sponsors who appeared to be very profit-driven, led consumers to perceive them as less credible. This resulted in a less positive attitude and response toward them (Rifon et al., 2004).

Hypothesis 5: The perceived profit-orientation of the corporate sponsor negatively influences consumers' attitude toward corporate sponsors of small-scale amateur sporting events.

\section{Method}

\section{Research Subjects}


Employing a convenience sampling method, the responses from 210 of the 229 subjects were regarded as valid. 19 questionnaires were removed due to incomplete or insincere responses, accounting for a $91.7 \%$ response rate. The respondents consisted of undergraduate students from four Singapore universities: Nanyang Technological University (48.1\%), National University of Singapore (28.1\%), Singapore Management University (11.9\%), and Singapore Institute of Management (11.9\%). The samples comprised 105 male (50\%) and 105 female (50\%) students. The respondents were recruited from various majors such as science, engineering, business, medicine, humanity and social science, and education. Racially, a large majority of the respondents were Chinese (91.4\%), followed by Indians (4.5\%), other racial groups (2.4\%) and Malays (1.9\%). Their ages ranged from 21 to 26 years old $(M=23.3, S D=1.3)$, and approximately $41.9 \%$ of the respondents were involved in small-scale amateur events for more than six times as actual participants.

\section{Instrument Development}

The questionnaire included three sections. The first section was designed to identify participants' perceptions of the different functions of corporate sponsors. Another section was to measure the participants' attitude toward corporate sponsors of small-scale amateur sporting events in Singapore. The final part of the questionnaire was developed to understand the demographic information of the respondents and their involvement level in small-scale amateur sporting events.

Independent measures. Five different functions of corporate sponsors were used to explore and understand consumers' perceptions of the sponsors for small-scale amateur sporting events. These five dimensions were established after being identified as common factors from various sponsorship literature and measured using a 7-point Likert-type scale. 
Perceived ubiquity of the sponsor was measured using four items, of which three items ( $\alpha$ $=.85$ ) were derived from Speed and Thompson (2000) and one was adapted from Alay (2008). Speed and Thompson (2000) conducted a focus group and a pretest to eliminate the items that performed poorly, while the modified item from Alay (2008) was originally from the Sponsorship Evaluation Questionnaire. All items reflected the frequency of corporate sponsors' involvement in sponsorship activities, as well as their level of focus. Perceived sincerity of the sponsor was measured using five items, of which four items $(\alpha=.88)$ were obtained from Speed and Thompson (2000), while one item was adapted from McDaniel and Mason (1999). Similarly, the items from Speed and Thompson (2000) were developed after a pilot study and a focus group, so as to increase the reliability and validity of the items. All five items reflected the motivation of corporate sponsors and their level of involvement in a small-scale sporting event. Perceived credibility of the sponsor was measured using three items $(\alpha=.89)$, which were directly taken from Erdem and Swait (2004). These items reflected the level of trustworthiness of the corporate sponsor. Perceived sponsor-event fit was measured using five items $(\alpha=.95)$. The items, obtained from Speed and Thompson (2000) after validity and reliability testing, reflected the degree of relevance and appropriateness between the sponsor and the small-scale sporting event. Perceived profit-orientation of the sponsor was measured using four items. Out of the four items, three items $(\alpha=.69)$ were developed by Rifon et al. (2004) and one was by Weight et al. (2010). The items reflected the corporate company's interest in making profits and its focus on generating sales, through sport sponsorship. Participants were asked to indicate their extent of agreement with each item, based on their experience and knowledge of a corporate sponsor of a small-scale amateur sporting event. 
Dependent measure. Attitude toward the corporate sponsor $(\alpha=.97)$ was measured using the four-item 7-point semantic differential scale, adapted from a study on attitude toward the advertiser (Bruner \& Hensel, 1992). The four items were represented by bad/good, dislike/like, unpleasant/pleasant, and unfavourable/favourable, anchored with one (bad, dislike, unpleasant, and unfavourable) and seven (good, like, pleasant, and favourable).

\section{Data Collection Procedure}

Data were collected using a survey questionnaire administered through Qualtrics, an online survey software. Participants had to read and understand the definition of small-scale amateur sporting events before doing the survey. The researcher emphasised that there were no right or wrong answers, assured participants that all responses would be kept confidential, and informed participants that they could withdraw from the study at any time without any consequence. The research procedures were cleared by the university's Institutional Review Board.

\section{Data Analysis}

The data were analysed using IBM Statistical Package for Social Science (SPSS 20.0). For the preliminary tests, descriptive statistics and internal consistency were examined to test for normality, multicollinearity, reliability and homoscedasticity of the measures. For the main test, a standard multiple regression analysis was performed to assess the influence of the independent variables (perceived ubiquity of the sponsor, perceived sincerity of the sponsor, perceived credibility of the sponsor, perceived sponsor-event fit and perceived profit-orientation of the sponsor) on the dependent variable (consumers' attitude toward the corporate sponsors of smallscale amateur sporting events in Singapore). An alpha level of .05 was utilised for all statistical tests. 


\section{Results}

For the preliminary tests, the descriptive statistics did not detect any outlier or invalid value. A test for normality of the data was conducted using skewness and kurtosis. Skewness values of the five perceived functions and the attitude dimension ranged from -.96 to .30, which were within the acceptable range of \pm 1.00 (Hair, Babin, Money, \& Samouel, 2003). Kurtosis values, which ranged from -.76 to .89 , were also within the acceptable range of \pm 3.00 (Hair et al., 2003). Cronbach's alpha coefficients were calculated to determine the internal consistency and reliability among the items in each dimension. As shown in Table 1, Cronbach's alpha ranged from .71 to .94 , indicating that all the dimensions for this study had an acceptable level of reliability among the items. After performing bivariate correlations among the independent and dependent variables, Pearson correlation revealed that there was no significant correlation between the perceived profit-orientation of the sponsor and consumers' attitude toward the corporate sponsor, as seen from Table 2. Therefore, perceived profit-orientation of the sponsor function was excluded in the further analysis.

For the main tests, multiple regression analyses were conducted to test the hypotheses. The results in Table 3 showed significant and positive relationship between perceived ubiquity of the sponsor $(p=.034)$ and consumers' attitude toward the sponsors, as well as perceived sponsor-event fit ( $p=.016)$ and consumers' attitude. However, there were no significant relationships between perceived sincerity of the sponsor and consumers' attitude as well as perceived credibility of the sponsor and consumers' attitude. Therefore, Hypothesis 4 was supported through this study. However, perceived ubiquity of the sponsor was found to exert a positive influence on consumers' attitude toward corporate sponsors instead, which was the opposite of Hypothesis 1. Hypothesis 2, 3, and 5 were not supported in this study. 


\section{Discussion}

\section{Possible Explanations for Differences in Relationships}

This study sought to investigate the relationships between the perceived functions of corporate sponsors and consumers' attitude toward these sponsors. Notably, the findings of this study revealed that perceived ubiquity of the sponsor positively influenced consumers' attitude toward corporate sponsors of small-scale amateur sporting events, which was a contrary to the hypothesis which proposed a negative relationship. A plausible explanation was that the scope of this study only involved small-scale amateur sporting events, in comparison to previous sponsorship literature, which expounded on large-scale sporting events. Sponsors of small-scale amateur sporting events may not need to be selective in their sponsorship to gain positive responses from consumers because small-scale amateur sporting events usually target a niche group of participants who are passionate about the sporting events (Miloch \& Lambrecht, 2006). As such, participants perceive corporate sponsors of small-scale events as being more involved in events that are highly regarded to them (Miloch \& Lambrecht, 2006). Consequently, participants may develop a more positive attitude toward sponsors of small-scale events, as revealed in this study.

Perceived sponsor-event fit was found to have positively influenced consumers' attitude toward corporate sponsors of small-scale amateur sporting events. This finding is congruent with previous sport sponsorship literature on large-scale sporting events. Understandably, consumers will develop negative feelings and psychological tensions, such as frustration, when they do not perceive the sponsor as appropriate for an event (Woisetschläger \& Michaelis, 2012). However, as small-scale events often attract consumers who are interested in and familiar with the sport, the positive feelings associated with their sporting interests can be transferred to the corporate 
sponsor of the event when there is a sponsor-event fit. This echoes the concept of image transfer (Woisetschläger \& Michaelis, 2012). Therefore, the results of this study imply that sponsor-event fit is a relevant and crucial function of sport sponsorships, regardless of the magnitude of the sporting event.

However, results from this study showed that perceived sincerity of the sponsor and perceived credibility of the sponsor did not influence consumers' attitude toward corporate sponsors of small-scale sporting events. As noted by Speed and Thompson (2000), perceived sincerity of the sponsor was determined by the frequency of the sponsorship as well as the motivations and commitments of the sponsor. Sponsors who were selective in their sponsorships were deemed as sincere sponsors, due to the large amount of effort committed to the event. However, this view was not reflected in the results as consumers of small-scale sporting events believed that it was more important for corporate sponsors to be ubiquitous than to be selective. This may be attributed to the limited funding received by small-scale events (Zinger \& O'Reilly, 2010). As such, consumers of small-scale sporting events are receptive toward having more sponsors to support the event. Hence, it is suggested that corporate sponsors do not have to be selective in their sponsorship. Additionally, they do not have to emphasise on portraying their sponsorships as forms of goodwill, rather than for commercial purposes.

Considerably, perceived credibility of the sponsor did not influence consumers' attitude toward the sponsor. This may be attributed to the fact that the participants may not be frequent consumers of small-scale amateur sporting events, and thus, pay less attention to the credibility of a sponsor for the event (Goldsmith, Lafferty, \& Newell, 2000). As mentioned earlier, consumers are more interested to have as many sponsors to fund and support the small-scale sporting events. Thus, the credibility of a sponsor may be less significant to consumers. 


\section{Implications of the Findings}

Most event management literature, especially in the local context, focus on large-scale sporting events. However, the approach to large-scale and small-scale events may be different, and the factors that affect participant's attitudes toward sponsorship may differ as well. The theory-driven findings from this study have a variety of potential applications. Sport sponsors can use the findings to develop successful sponsorship which builds a positive attitude toward sponsorship. First, perceived ubiquity of the sponsor is an important function for small-scale amateur sporting events in Singapore. Corporate sponsors should consider being more actively involved in more small-scale sporting events. Given the difficulties faced by organisers of smallscale sporting events in getting funding, consumers of small-scale events would tend to develop a sense of gratitude toward these sponsors, which would translate to greater purchase intent (Miloch \& Lambrecht, 2006). On this premise, sponsorship effectiveness may be achieved as the amount of benefits attained from sponsoring multiple small-scale events may leapfrog the amount of benefits accrued from sponsoring a single large-scale sporting event.

Furthermore, as it is crucial for the sporting event and the corporate sponsors to have a good fit, corporate sponsors should target sporting events that better match their corporate images. Additionally, corporate sponsors should craft taglines and slogans or revamp their company images such that they become more aligned toward the nature of the sponsored events. On the other end, event organisers should also be more convinced and confident in approaching corporate companies that have a strong fit with their events, based on the positive value of fit as affirmed by this study.

Finally, the results of this study have also illuminated that sponsorship proposals should not adopt a one-size-fits-all approach. Instead, sponsorship proposals from event organisers 
should be tailored to enhance the sponsorship effectiveness for both the corporate sponsors and themselves. With more corporate sponsors drawn on board, event organisers can then have a greater clout to promote their events and to champion a better event for both the participants and the sponsors.

\section{Limitations and Future Studies}

There are some limitations in this study that need to be addressed. Firstly, survey respondents were confined to only undergraduate students in Singapore, which limited the generalisability of the results. Therefore, future studies can include other demographic groups (e.g., age, gender, occupation, etc.) or psychographic groups (e.g., habits, lifestyle, social class, etc.), who may represent salient target groups for corporate sponsors of small-scale sporting events. Future research should include more participants who are highly involved in small-scale events, as their responses to corporate sponsors may differ from average sport consumers. Secondly, the items in the survey were selected from different studies that focused on large-scale sporting events. As such, some items had been further developed to suit the context of the study, which could have influenced the reliability and validity issues. Therefore, it is essential to develop a scale that directly measures the perceived functions of corporate sponsors for smallscale amateur sporting events for future research. Lastly, more perceived functions should be incorporated, to provide a more extensive framework to better understand corporate sponsorship in small-scale amateur sporting events.

\section{Conclusion}

As sponsorship literature that focuses on small-scale amateur sporting events is sparse, this study concentrated on identifying the perceived functions of corporate sponsors that encouraged consumers to develop a positive attitude toward the corporate sponsors of small- 
scale amateur sporting events. From this study, perceived ubiquity and perceived sponsor-event fit were identified as the two main functions. The positive influence of perceived ubiquity of the sponsor on consumers' attitude was a surprise finding as perceived ubiquity negatively influenced consumers' attitude toward the sponsors of large-scale sporting events. Considerably, the results and knowledge from this study will be beneficial to event organisers and potential sponsors of small-scale sporting events. Corporate companies that are interested in sponsoring sporting events should consider sponsoring many small-scale events to increase their brand awareness as well as to focus on events that have a closer fit to their company images. Moreover, as the results from this study have identified the differences in consumers' attitude toward sponsors of small-scale and large-scale sporting events, event organisers should develop sponsorship proposals that are more specific to small-scale sporting events.

Looking ahead, as the sponsorship market for large-scale sporting events becomes increasingly saturated and expensive, corporate companies should consider shifting their attention to small-scale sporting events. With greater support from corporate companies, more sporting events can be organised to encourage people to be actively involved in the sporting scene. Ultimately, the reliance on funding and support from the government would be reduced and more funding can be channeled to other aspects of nation building, as Singapore works toward becoming a true sporting nation. 


\section{References}

Abratt, R., \& Grobler, P. S. (1989). The evaluation of sports sponsorships. International Journal of Advertising, 8(4), 351-362.

Ajzen, I. (2001). Nature and operation of attitudes. Annual Review of Psychology, 52(1), 27-58. doi:10.1146/annurev.psych.52.1.27

Alay, S. (2008). Female consumers' evaluations of sponsorship and their response to sponsorship. South African Journal for Research in Sport, Physical Education and Recreation, 30(2), 15-29.

Alexandris, K., Tsaousi, E., \& James, J. (2007). Predicting sponsorship outcomes from attitudinal constructs: The case of a professional basketball event. Sport Marketing Quarterly, 16, 130-139.

Asiegbu, I., Powei, D., \& Iruka, C. (2012). Consumer attitude: Some reflections on its concept, trilogy, relationship with consumer behaviour, and marketing implications. European Journal of Business and Management, 4(13), 38-50.

Assimakopoulos, A. (1993). Corporate sport sponsorship in Greece: Perception of knowledge, attitude and involvement of business executives, sport administrators, and advertising executives (Unpublished doctoral dissertation). The Ohio State University, Columbus, Ohio.

Baek, T. H., Kim, J., \& Yu, J. H. (2010). The differential roles of brand credibility and brand prestige in consumer brand choice. Psychology \& Marketing, 27(7), 662-678. doi:10.1002/mar.20350

Baum, T., \& Lockstone, L. (2007). Volunteers and mega sporting events: Developing a research framework. International Journal of Event Management Research, 3(1), 29-41. 
Bruner, G. C., \& Hensel, P. J. (1992). Marketing scales handbook. Chicago: American Marketing Association.

Carrillat, F., \& D'Astous, A. (2013). The complementarity factor in the leveraging of sponsorship. International Journal of Sports Marketing \& Sponsorship, 15(1), 20-39.

Chan, M. (n.d.). The inaugural Youth Olympic Games as a catalyst for sports tourism in Singapore. Retrieved from http://qmss.columbia.edu/storage/qmss-pdf-files/studenttheses/Chan_Michelle-\%20Inaugural\%20Youth\%20Olympic\%20Games.pdf

Copeland, R., \& Frisby, W. (1996). Understanding the sport sponsorship process from a corporate perspective. Journal of Sport Management, 10, 32-48.

Department for Culture, Media and Sport. (2012). Creating a sporting habit for life: A new youth sport strategy. Retrieved from https://www.gov.uk/government/uploads/system/ uploads/attachment_data/file/78318/creating_a_sporting_habit_for_life.pdf

Dixon, A., Henry, M., \& Martinez, J. (2013). Assessing the economic impact of sport tourists' expenditures related to a university's baseball season attendance. Journal of Issues in Intercollegiate Athletics, 6, 96-113.

Eagleman, A., \& Krohn, B. (2012). Sponsorship awareness, attitudes, and purchase intentions of road race series participants. Sport Marketing Quarterly, 21, 210-220.

Erdem, T., \& Swait, J. (2004). Brand credibility, brand consideration and choice. Journal of Consumer Research, 31, 191-198. doi:10.1086/383434

Fishbein, M., \& Ajzen, I. (1975), Belief, attitude, intention, and behavior: An introduction to theory and research. Reading, MA: Addison-Wesley.

Goldsmith, R. E., Lafferty, B. A., \& Newell, S. J. (2000). The influence of corporate credibility on consumer attitudes and purchase intent. Corporate Reputation Review, 3(4), 304-318. 
doi:10.1057/palgrave.crr.1540122

Gwinner, K. (1997). A model of image creation and image transfer in event sponsorship. International Marketing Review, 14(3), 145-158. doi:10.1108/02651339710170221

Hair, J., Babin, B., Money, A., \& Samouel, P. (2003). Essentials of business research. New York: John Wiley \& Sons.

Hanzaee, K., \& Taghipourian, M. (2012). The effects of brand credibility and prestige on consumers purchase intention in low and high product involvement. Journal of Basic and Applied Scientific Research, 2(2), 1281-1291.

Higham, J. (1999). Sport as an avenue of tourism development: An analysis of the positive and negative impacts of sport tourism. Current Issues in Tourism, 2, 82-90. doi:10.1080/13683509908667845

Hlabane, B. (n.d.). Sociology of sports mega events: A tourism perspective. Retrieved from http: //www.apu.ac.jp/rcaps/uploads/fckeditor/publications/journal/RJAPS_V28_Bheki.pdf

Hoi, N. Y. (1999). Sport sponsorship in Singapore: A study of corporate sponsors' selection and evaluation criteria: Their implications for sport organisations and business corporations (Unpublished master's thesis). Nanyang Technological University, Singapore.

International Olympic Committee (2013). Factsheet: London 2012 facts \& figures. Retrieved from http://www.olympic.org/Documents/Reference_documents_Factsheets/London2012-Fact-Sheet-in-track-FINAL-qc-V3-One-year-on-qc.pdf

Jordan, C. (2012, December 13). Singapore as a global sports hub and its effects to the economy. Singapore Business Review. Retrieved from http://sbr.com.sg/leisure-entertainment/ commentary/singapore-global-sports-hub-and-its-effects-economy

Keller, K. (1993). Conceptualising, measuring, and managing customer-based brand equity. 
Journal of Marketing, 57(1), 1-22. doi:10.2307/1252054

Keller, K. (2003). Brand synthesis: The multidimensionality of brand knowledge. Journal of Consumer Research, 29(4), 595-600. doi: 10.1086/346254

Kim, Y. K., Ko, Y. J., \& James, J. (2011). The impact of relationship quality on attitude toward a sponsor. Journal of Business \& Industrial Marketing, 26(8), 566-576.

Kng, Z. G. (2013, September 30). Smaller-scale tournaments to benefit back-up and junior players. The Star. Retrieved from http://www.thestar.com.my/Sport/Squash/2013/09/ 30/Smaller-scale-tournaments-to-benefit-back-up-and-junior-players.aspx/

Koo, G. Y., Quarterman, J., \& Flynn, L. (2006). Effect of perceived sport events and sponsor image fit on consumer's cognition, affect, and behavioural intentions. Sports Marketing Quarterly, 15, 80-90.

Lim, S. H. (2012, July 14). Sponsorship boost for Singapore National Games. The New Paper. Retrieved from http://news.asiaone.com/News/Latest\%2BNews/Sports/Story/ A1Story20120712-358729.html

Mack, R. (1999). Event sponsorship: An exploratory study of small business objectives, practices and perceptions. Journal of Small Business Management, 37(3), 25-30.

Madrigal, R. (2001). Social identity effects in a belief-attitude-intentions hierarchy: Implications for corporate sponsorship. Psychology \& Marketing, 18(2), 145-165. doi: 10.1002/15206793(200102)18:2<145::AID-MAR1003>3.0.CO;2-T

McDaniel, S. (1999). An investigation of match up effects in sport sponsorship advertising: The implications of consumer advertising schemas. Psychology \& Marketing, 16(2), 163-184. doi: 10.1002/(SICI)1520-6793(199903)16:2<163::AID-MAR6>3.0.CO;2-Y

McDaniel, S. R., \& Mason, D. S. (1999). An exploratory study of influences on public opinion 
towards alcohol and tobacco sponsorship of sporting events. Journal of Services Marketing, 13(6), 481-499. doi: 10.1108/08876049910298757

McDonald, C. (1991). Sponsorship and the image of the sponsor. European Journal of Marketing, 25(11), 31-38. doi:10.1108/EUM0000000000630

Meenaghan, J. (1983). Commercial sponsorship. European Journal of Marketing, 17(7), 5-73. doi: 10.1108/EUM0000000004825

Meenaghan, T. (1991). Sponsorship: Legitimising the medium. European Journal of Marketing, 25(11), 5-10. doi: 10.1108/EUM0000000000627

Meenaghan, T. (2001). Understanding sponsorship effects. Psychology \& Marketing, 18(2), 95121. doi: 10.1002/1520-6793(200102)18:2<95::AID-MAR1001>3.0.CO;2-H

Miloch, K., \& Lambrecht, K. (2006). Consumer awareness of sponsorship at grassroots sport events. Sport Marketing Quarterly, 15, 147-154.

Ministry of Culture, Community and Youth (2010). Singapore 2010 Youth Olympic Games: Blazing the trail, official report. Retrieved from http://app.mccy.gov.sg/Portals/0/ Summary/publication/SD/Singapore\%202010\%20Official\%20Report\%20\%20Blazing\%20the\%20Trail\%20English19MB.pdf

Misra, S., \& Beatty, S. E. (1990). Celebrity spokesperson and brand congruence: An assessment of recall and affect. Journal of Business Research, 21(2), 159-173. doi: 10.1016/01482963(90)90050-N

Pham, M. T., \& Johar, G. V. (2001). Market prominence biases in sponsor identification: Processes and consequentiality. Psychology and Marketing, 18(2), 123-143. doi:10.1002/1520-6793(200102)18:2<123::AID-MAR1002>3.0.CO;2-3

Rifon, N. J., Choi, S. M., Trimble, C. S., \& Li, H. (2004). Congruence effects in sponsorship: The 
mediating role of sponsor credibility and consumer attributions of sponsor motive. Journal of Advertising, 33(1), 29-42. doi:10.1080/00913367.2004.10639151

Roche, M. (2000). Mega-events: Olympics and expos in the growth of global culture. London: Routledge.

Ruth, J. A., \& Simonin, B. L. (2003). Brought to you by brand A and brand B: Investigating multiple sponsors' influence on consumers' attitudes toward sponsored events. Journal of Advertising, 32(3), 19-30. doi:10.1080/00913367.2003.10639139

See, Y. H., Petty, R. E., \& Fabrigar, L. R. (2008). Affective and cognitive meta-bases of attitudes: Unique effects on information interest and persuasion. Journal of Personality and Social Psychology, 94(6), 938-955. doi: 10.1037/0022-3514.94.6.938

Shahrokh, Z. D., Khazaee, S., \& Hashemi, A. R. (2013). The effect of the attitude, the mental involvement and the good will of sport fans on the purchase intention of the products of the sponsor company. Journal of Basic and Applied Scientific Research, 3(4), 92-99.

Simmons, C. J., \& Becker-Olsen, K. L. (2006). Achieving marketing objectives through social sponsorships. Journal of Marketing, 70, 154-169. doi: 10.1509/jmkg.70.4.154

Speed, R., \& Thompson, P. (2000). Determinants of sports sponsorship response. Journal of the Academy of Marketing Science, 28(2), 226-238. doi: 10.1177/0092070300282004

Stipp, H., \& Schiavone, N. (1996). Modeling the impact of Olympic sponsorship on corporate image. Journal of Advertising Research, 36(4), 22-28.

Tzetzis, G., Alexandris, K., \& Kapsampeli, S. (2014). Predicting visitors' satisfaction and behavioral intentions from service quality in the context of a small-scale outdoor sport event. International Journal of Event and Festival Management, 5(1), 4-21. doi:10.1108/IJEFM-04-2013-0006 
Vision 2030 (n.d.). Sustainable funding. Retrieved from http://www.vision2030.sg/proposals/ sustainable-funding/

Walker, M., Hall, T., Todd, S., \& Kent, A. (2011). Does your sponsor affect my perception of the event? The role of event sponsors as signals. Sport Marketing Quarterly, 20, 138-147.

Walo, M., Bull, A., \& Breen, H. (1996). Achieving economic benefits at local events: A case study of a local sports event. Journal of Festival Management and Event Tourism, 4(3), 95-106.

Weight, E., Taylor, K., \& Cuneen, J. (2010). Corporate motives for sport sponsorship at midmajor collegiate athletic departments. Journal of Issues in Intercollegiate Athletics, 3, 119-130.

Woisetschläger, D. M., \& Michaelis, M. (2012). Sponsorship congruence and brand image. European Journal of Marketing, 46(3/4), 509-523. doi:10.1108/03090561211202585

Yusof, A., Omar-Fauzee, M., Shah, P., \& Geok, S. K. (2009). Exploring small-scale sport event tourism in Malaysia. Research Journal of Internatıonal Studıes, 9, 47-58.

Zinger, J., \& O'Reilly, N. (2010). An examination of sports sponsorship from a small business perspective. International Journal of Sports Marketing \& Sponsorship, 11(4), 283-301. 
Table 1

Descriptive Statistics of the Measures

\begin{tabular}{lccccc}
\hline Item & Mean & SD & Skewness & Kurtosis & Cronbach's Alpha \\
\hline Ubiquity 1 & 4.97 & 1.34 & -.66 & .03 & .59 \\
Ubiquity 2 & 5.10 & 1.38 & -.96 & .50 & .72 \\
Ubiquity 3 & 5.17 & 1.38 & -.85 & -.72 & \\
Ubiquity 4 & 3.78 & 1.50 & .10 & .30 & \\
Sincerity 1 & 4.71 & 1.22 & -.47 & -.70 & .77 \\
Sincerity 2 & 4.20 & 1.38 & -.21 & -.76 & \\
Sincerity 3 & 3.94 & 1.47 & -.05 & -.63 & .86 \\
Sincerity 4 & 4.25 & 1.42 & -.27 & .24 & \\
Sincerity 5 & 5.15 & 1.29 & -.69 & .20 & .28 \\
Credibility 1 & 4.94 & 1.08 & -.32 & -.21 & \\
Credibility 2 & 5.08 & 1.03 & -.56 & -.06 & \\
Credibility 3 & 4.71 & 1.06 & -.24 & -.27 & \\
Fit 1 & 4.93 & 1.29 & -.64 & .56 & \\
Fit 2 & 4.84 & 1.27 & -.39 & .05 & \\
Fit 3 & 5.04 & 1.14 & -.71 & .48 & \\
Fit 4 & 4.68 & 1.25 & -.59 & -.15 & \\
Fit 5 & 4.97 & 1.23 & -.66 & .34 & \\
Profit 1 & 4.70 & 1.35 & -.43 & -.16 & \\
Profit 2 & 5.30 & 1.17 & -.63 & .46 & \\
Profit 3 & 4.02 & 1.26 & .30 & -.37 & \\
Profit 4 & 5.59 & 1.21 & -.77 & \\
Attitude 1 & 5.33 & 1.02 & -.03 & .13 & \\
Attitude 2 & 5.27 & 1.00 & .13 & \\
Attitude 3 & 5.32 & .96 & -.06 & -.40 & \\
Attitude 4 & 5.29 & 1.05 & & & \\
\hline & & & & \\
\end{tabular}


Table 2

Pearson Correlation Coefficient among the Constructs

\begin{tabular}{lcccccc}
\hline & Ubiquity & Sincerity & Credibility & Fit & Profit & Attitude \\
\hline Ubiquity & 1 & & & & \\
Sincerity & $.44^{*}$ & 1 & & & \\
Credibility & $.41^{*}$ & $.55^{*}$ & 1 & & \\
Fit & $.21^{*}$ & $.40^{*}$ & $.50^{*}$ & 1 & \\
Profit & .09 & -.06 & -.01 & .05 & 1 & \\
Attitude & $.24 *$ & $.20^{*}$ & $.27^{*}$ & $.28^{*}$ & -.06 & 1 \\
*Significant at .05. & & & & & &
\end{tabular}


Table 3

Regression Coefficients

\begin{tabular}{lcccc}
\hline Function & Standardised Coefficient & $\begin{array}{c}\text { Standard } \\
\text { Error }\end{array}$ & $t$ & $p$ \\
\hline Ubiquity & .16 & 0.07 & 2.13 & .034 \\
Sincerity & -.01 & 0.08 & -.13 & .897 \\
Credibility & .12 & 0.09 & 1.37 & .173 \\
Fit & .19 & 0.07 & 2.42 & .016 \\
\hline
\end{tabular}

